\title{
Acute urinary retention after venlafaxine use
}

\author{
Şaban Oğuz Demirdöğen ${ }^{1}$, Esen Yıldırım Demirdöğen ${ }^{2}$, Şenol Adanur ${ }^{1}$ \\ ${ }^{1}$ Urology Department Atatürk University, Turkey; \\ 2 Department of Child and Adolescent Psychiatry Atatürk University, Turkey.
}

\begin{abstract}
Summary We describe a case of lower urinary system symptoms (LUSSs) and acute urinary retention that developed after treatment with a low dose of venlafaxine. A 48-year-old male patient was admitted to our clinic because of difficulty urinating, an intermittent stream, and trickling at the end of urination, together with urinary retention that had started about 45 days ago. The patient had been taking venlafaxine for the previous 6 months. The drug had been prescribed by the psychiatry department for a diagnosis of major depression, and the dose had been increased from 75 mg/day to $150 \mathrm{mg} /$ day 1.5 months earlier. The patients' symptoms were thought to be related to venlafaxine, and the symptoms disappeared completely after venlafaxine was replaced with agomelatine. We concluded that the LUSSs and urinary retention were due to the venlafaxine treatment.
\end{abstract}

KEY WORDS: Acute urinary retention; Lower urinary tract symptoms; Venlafaxine.

Submitted 17 December 2016; Accepted 11 January 2017

\section{INTRODUCTION}

Lower urinary system symptoms (LUSSs) consist of symptom subtypes related to urinary storage and drainage. LUSSs are an important health problem due to their negative effects on quality of life. Acute urinary retention develops due to an inability to urinate and results in a full and tense bladder, together with suprapubic pain and tenderness. The most common cause of LUSSs is benign prostate hyperplasia. Acute urinary retention can develop due to genitourinary system tumors, vesical or urethral stones, urethral strictures, and medications, in addition to acute prostatitis and neurological diseases (1).

Several case reports have described venlafaxine-related acute urinary retention when the drug was used in combination and in high doses. We describe a case of LUSSs and acute urinary retention that developed following the use of low-dose venlafaxine monotherapy.

\section{Case report}

A 48-year-old male patient with a diagnosis of major depression presented to our clinic with LUSSs, which included difficulty urinating, an intermittent stream, and trickling at the end of urination, together with an inability to urinate. The symptoms had lasted for about $20 \mathrm{~h}$ and had started after the venlafaxine dosage had been increased from $37.5 \mathrm{mg}$ twice daily $(75 \mathrm{mg} /$ day) to 75 mg twice daily $(150 \mathrm{mg} /$ day $) 1.5$ months earlier. The patient had no history of significant disease or abdominal or urologic surgery, and his family history revealed nothing of significance. A physical examination revealed a vesical globe. Kidney-ureter-bladder film was normal. No pathology was observed in the abdomen or urinary system on ultrasonography, and no pathology was found on cranial and lumbar magnetic resonance images.

A transurethral (TU) catheter was placed, as the patient had a vesical globe. A urine culture was sterile.

The results of urodynamic tests were normal. No urogenital system pathology was found that could explain the patient's condition, and a psychiatry consultation was therefore requested to evaluate whether the problem was associated with the venlafaxine treatment.

The psychiatry department suggested that the patients' symptoms were related to venlafaxine. Thus, the dose of venlafaxine (150 mg/day) was decreased gradually and discontinued after five days.

The patient was prescribed a daily dose $(25 \mathrm{mg})$ of agomelatin, which is a melatoninergic receptor agonist antidepressant.

The TU was removed one day after the dose of venlafaxine was decreased to $37.5 \mathrm{mg}$ twice a day, and urination was monitored. The TU was inserted again when the patient developed a vesical globe. The TU catheter was removed three days after venlafaxine was discontinued. During uroflowmetry, the patient was unable to urinate freely $\left(\mathrm{Q}_{\max } 3 \mathrm{ml} / \mathrm{s}\right)$, but no significant postvoiding residual urine (PVR) was seen in the bladder. Uroflowmetry was repeated the next day. The $Q_{\max }$ was $8.1 \mathrm{ml} / \mathrm{s}$, with no significant PVR. The patient was discharged and advised to continue taking his current medical treatment. At outpatient follow-up 10 days later, the symptoms had disappeared completely, the $\mathrm{Q}_{\max }$ was 19.3 $\mathrm{ml} / \mathrm{s}$, and the PVR was $10 \mathrm{cc}$ on uroflowmetry.

\section{Discussion}

Venlafaxine belongs to the serotonin-noradrenalin reuptake inhibitor group and exerts its effects by blocking serotonin, noradrenalin and, at high doses, dopamine uptake bidirectionally. It is used to treat major depression and anxiety. It is administered orally and is a safe drug that can usually be tolerated (2). The effects of ven- 
lafaxine are similar to those of tricyclic antidepressants, which also affect serotonin and noradrenalin receptors, but it has relatively few side effects due to its lack of affinity to other receptors. The most common side effects are nausea, somnolence, dry mouth, dizziness, irritability, constipation, asthenia, anxiety, anorexia, blurred vision, abnormal ejaculation or orgasm, and impotence. However, these effects are usually mild and rarely require treatment cessation. In addition to the above-mentioned side effects, hypertension was reported to be a common problem among patients taking venlafaxine (3). Due to its tolerability and few side effects mentioned above, venlafaxine is considered a good option for patients with major depression.

LUSSs and acute urinary retention can occur following the use of opiates, antihistamines, alpha adrenergic agonists, ganglion blockers, phenothiazines, and monoamino oxidase (MAO) inhibitors. These findings are attributed to the contraction of the urethral sphincter muscle as a result of anticholinergic stimulation (4). Previous studies also showed that LUSSs and acute urinary retention developed following treatment with antidepressant and antipsychotic drugs. The development of LUSSs was reported after the use of duloxetine, a selective serotonin noradrenalin reuptake inhibitor (5) and milnasipram, another antidepressant (6). Urinary side effects, such as urinary incontinence, related to venlafaxine have previously been reported in the literature $(7,8)$, and several cases of LUSSs and acute urinary retention following the use of venlafaxine were reported. However, these side effects only occurred when venlafaxine was used in combination with another drug or when venlafaxine was administered at high doses (375 mg once daily) when used as monotherapy $(9,10)$.

Our case is important, as it is the first report of the development of LUSSs and acute urinary retention when venlafaxine was used as monotherapy and at a low dose.

LUSSs and acute urinary retention are thought to be due to adrenergic stimulation, which occurs as a result of venlafaxine inhibiting noradrenaline reuptake. These side effects can be severe and can interfere with the continuation of treatment, as in the present case. Despite these side effects, in a limited patient series, venlafaxine was reported to increase the quality of life of patients with neurological disorders by reducing their daily urination frequency and increasing their bladder capacity (11).

In the present case, agomelatine, which is used to treat depression and sleep disorders, was thought to be a safer option than venlafaxine due to its lack of interaction with the relevant receptors and the patient's clinical condition, and no urinary tract side effects were observed.

\section{Conclusion}

Venlafaxine is a safe and effective antidepressant for the treatment of major depression and anxiety disorders. However, it may not be suitable for patients with accompanying prostate disease or micturition disorders. Prior to prescribing venlafaxine, it should be considered that venlafaxine monotherapy can cause LUSSs and urinary retention.

\section{References}

1. Irwin DE, et al., Population-based survey of urinary incontinence, overactive bladder, and other lower urinary tract symptoms in five countries: results of the EPIC study. Eur Urol. 2006; 50:1306-14.

2. Stahl SM. Stahl's essential psychopharmacology: neuroscientific basis and practical applications. 2013: Cambridge University Press.

3. Rudolph RL, Derivan AT. The safety and tolerability of venlafaxine hydrochloride: analysis of the clinical trials database. J Clin Psychopharmacol. 1996; 16(3 Suppl 2): p. 54S-59S.

4. Cardozo L. Voiding difficulties and retention. Urogynecology, 1st ed., 1997, New York, NY: Churchill Livingstone, 305-320.

5. Thor KB, Katofiasc MA. Effects of duloxetine, a combined serotonin and norepinephrine reuptake inhibitor, on central neural control of lower urinary tract function in the chloralose-anesthetized female cat. J Pharmacol Exp Ther. 1995; 274:1014-24.

6. Akpınar A. Milnasipran Tedavisine Bağh Ani Gelişen Prostatizm: Bir Olgu Sunumu. Türk Psikiyatri Dergisi. 2009; 20:403.

7. Polimeni G, Salvo F, Cutroneo P, et al. Venlafaxine-induced urinary incontinence resolved after switching to sertraline. Clin Neuropharmacol. 2005; 28:247-8.

8. Selvaraj V, Gunasekar P, Kumar S, Alsakaf I. Urinary Incontinence due to Overactive Detrusor Muscle: A Rare Side Effect of Venlafaxine. Case Rep Urol. 2015; 690931.

9. Alexander J, McKenny B, Chaudhary J. Venlafaxine associated urinary symptoms. Aust N Z J Psychiatry. 2010; 44:1145.

10. Benazzi F. Urinary retention with venlafaxine-haloperidol combination. Pharmacopsychiatry. 1997; 30:27.

11. Inghilleri $M$, Conte A, Frasca V, et al. Venlafaxine and bladder function. Clin Neuropharmacol. 2005; 28:270-3.

\section{Correspondence}

Saban Oğuz Demirdöğen, MD

oguzdemirdogen@hotmail.com

Senol Adanur, MD

s.adanur61@hotmail.com

Atatürk University Urology Department, Turkey

Esen Yildırım Demirdöğen, MD esenyildirim08@hotmail.com

Atatürk University Department of Child and Adolescent Psychiatry, Turkey 